\title{
Ageism in Belgium and Burundi: a comparative analysis
}

\author{
Manon Marquet \\ Pierre Missotten \\ Sarah Schroyen \\ Desiderate Nindaba \\ Stéphane Adam \\ Psychology of Aging Unit, University \\ of Liège, Liège, Belgium
}

\author{
This article was published in the following Dove Press journal: \\ Clinical Interventions in Aging \\ 24 August 2016 \\ Number of times this article has been viewed
}

Background: Recent cross-cultural comparisons between Asian and Western cultures have shown that ageism arises more from the lack of availability of social and economic resources for older adults than from the culture itself. We tested this assumption by conducting a survey among people living in a least developed country compared with those living in a developed country.

Participants and methods: Twenty-seven Belgians living in Belgium, 29 Burundians living in Belgium, and 32 Burundians living in Burundi were included in this study. Their attitudes toward older adults were assessed using several self-reported measures.

Results: Statistical analyses confirmed that older people are more negatively perceived by Burundians living in Burundi than by Burundians and Belgians living in Belgium, whose attitudes did not differ from each other.

Conclusion: Consistent with our hypothesis, our results suggest that the level of development of a country and more particularly the lack of government spending on older people (pension and health care systems) may contribute to their younger counterparts perceiving them more negatively.

Keywords: attitudes toward older adults, cross-cultural differences, socioeconomic development, intergenerational relations

\section{Introduction}

As the older population has grown faster than the total population, the proportion of older people relative to the rest of the population has considerably increased: $9.2 \%$ of the world's population was at least 60 years of age in 1950, and this number has now risen to $11.7 \%$ in 2013 and is projected to reach $21.1 \%$ in $2050 .{ }^{1}$ This population aging raises questions about attitudes toward older adults and cross-cultural differences in these attitudes. In Western societies (eg, the United States and Western European countries), the rapid aging of the world's population is associated with a view of aging that is deeply focused on decline. These essentially negative stereotypes allude to the concept of "ageism", ${ }^{2}$ which refers to negative attitudes toward the elderly. According to the stereotype content model, ${ }^{3}$ even if older people are considered to be warm by younger individuals, they are often stereotyped as physically and cognitively inept because they are perceived to be of low status and noncompetitive. ${ }^{4,5}$

There is some reason to believe that East Asian cultures (eg, People's Republic of China, Japan, Korea) may be less ageist, given their greater emphasis on Confucian values of filial piety that involve respect for elders and children's obligation to care for their aging parents physically, emotionally, and financially. ${ }^{6}$ These cultures, as Southeast Asian cultures (eg, India), are collectivism oriented and place a strong emphasis on interdependence among people and particularly among all members of the family, honoring and supporting older people and committing oneself to family
Correspondence: Manon Marquet Psychology of Aging Unit, University of Liège, Quartier Urbaniste I, Traverse des Architectes (B63c), B-4000 Liège, Belgium Tel +32 43665716

Email mmarquet@ulg.ac.be (c)
hereby accept the Terms. Non-commercial uses of the work are permitted without any further permission from Dove Medical Press Limited, provided the work is properly attributed. For permission for commercial use of this work, please see paragraphs 4.2 and 5 of our Terms (https://www.dovepress.com/terms.php). 
obligations. However, individualist Western cultures focus on self-centered satisfaction and interest as well as freedom and individuality. ${ }^{7}$

Different studies have tested this hypothesis and established cross-cultural comparisons of ageism among young adults with Eastern and Western cultures. Although some studies confirmed that attitudes toward older adults are more positive in Asian than in Western cultures, ${ }^{8}$ others reported opposite results ${ }^{9,10}$ or no difference. ${ }^{5,11}$ For example, a crosscultural study conducted among collectivist cultural samples (ie, college students in Hong Kong, Japan, and South Korea) showed that the incompetent-but-warm stereotype is held quite universally, without differences between collectivist and individualistic cultures. ${ }^{5}$ Moreover, a study conducted among participants in their early 20s across 26 cultures including both Asian (eg, Hong Kong, India, Japan, Mainland China, South Korea) and Western cultures (eg, Croatia, the Czech Republic, Estonia, France, Great Britain, Poland, Portugal, USA) showed cross-cultural consensus that physical attractiveness and the ability to perform everyday tasks and learn new information decrease with age. In turn, general knowledge and wisdom are believed to increase with age. ${ }^{11}$

According to these results, the cultural expectation that Eastern cultures are less ageist than Western cultures because they place a stronger emphasis on collectivist traditions of filial piety is not well supported by the literature. This observation questions the comparison of Eastern and Western cultures only in terms of cultural traditions (collectivist versus individualistic) and suggests that other social and economic forces may have a more important role to play when establishing cross-cultural comparisons of attitudes toward older adults.

\section{Predictors of attitudes toward the aged across cultures The role of modernization}

One possible explanation for the contrasting results when comparing ageism between the East and West concerns the old traditions and values regarding aging in East Asian cultures, which have been changing as a consequence of modernization. Modernization, ${ }^{12,13}$ by decreasing the status and competitiveness of older people, may contribute to explaining the presence of the incompetent-but-warm stereotype both in Western and Eastern countries. Progress in medical treatment favors aging of the population, which institutionalizes retirement and prevents older people from holding prestigious jobs. Moreover, technological advances eclipse experience and create new jobs, for which older people are not trained, which puts them out of work. Urbanization also takes young people away from their homes to find a job. In addition, younger people currently rely more on Internet-based knowledge rather than on oral traditions, which eliminates the elders' long-held position as transmitter of cultural knowledge and wisdom. Although modernization processes transform the physical environment surrounding relationships with family and friends, it seems that the importance of collectivistic living may be valued even during a period of significant economic development. For example, a study showed that Japanese continue to value family and friends, probably in a less obligatory and more voluntary manner today compared to previous decades. ${ }^{14}$ Moreover, ageism focuses on a particular group. Cultures may continue to hold collectivist values in general while perceiving older adults more negatively because of the process of modernization. These social, economic, and technological changes have taken place in all modern countries, so that despite collectivistic tendencies in some societies, similarities in the structure of ageism are to be expected when a shift toward modernization is present. These results, however, need to be further specified. Recent studies suggest that the impact of modernization on ageism is not a linear phenomenon. ${ }^{15,16}$

\section{The role of socioeconomic resources}

In their meta-analysis comparing Eastern and Western attitudes toward older people, North and Fiske ${ }^{15}$ found that attitudes are moderately more negative among Eastern than Western cultures, irrespective of the sample age distribution. By analyzing moderators accounting for this difference between cultures, they found that industrialization (ie, change over time of the gross domestic product) per se may not predict attitudes toward the aged. Population aging and more particularly the old-age dependency ratio (the number of persons aged 65 years or older per 100 persons of working age [15-64 years old]) are better predictors of negative attitudes toward older adults than industrialization alone. Similarly, a study conducted among middle-aged people (from 39 years to 53 years) in the European region showed that even though the perceived status of older people declines in the early stages of modernization, ${ }^{16}$ it may increase in more advanced stages of modernization because the funds allocated to support older people also increase (eg, pension, health care system). When societies have progressed beyond early stages of modernization, as is the case with European countries, people in more modern countries, which are assessed in terms of societal development in health, education, income, and levels of urbanization (eg, Belgium, Denmark, Sweden), have 
more favorable perceptions of the status of older people than people living in less modern countries (eg, Turkey, Romania, Croatia). This study also showed that the employment rate of older adults moderates this result. Perceptions of the social status of older people are likely to be similar between modern and less modern countries if the proportion of older people who are employed is high. However, when the percentage of employment is low, older people in less modern countries are perceived to have significantly lower status compared with more modern countries and also countries with higher elder employment rates. These results suggest that the impact of modernization on attitudes toward the aged is not linear and is more a question of economic resources.

\section{Aging in Sub-Saharan African cultures}

These results raise the question of how older people are perceived in the least developed countries in the world, which are primarily located in Sub-Saharan Africa. ${ }^{17}$ The least developed countries represent the poorest and weakest segment of the international community. They are characterized by a low income, weak human resources, and a low level of economic diversification. ${ }^{18}$ Traditionally, ${ }^{19}$ filial piety and cooperation within and between generations have been important in African cultures. Intergenerational family solidarity ensures the welfare of the vulnerable young, the old, and the bereaved (widows and orphans). However, SubSaharan countries are currently undergoing a multitude of demographic, economic, and social transformations that are likely to modify traditions of solidarity.

Thus, we observed that, globally, the older population is growing faster in the less developed regions (ie, Africa, Latin America, the Caribbean, Asia, and Oceania - excluding Japan, Australia, and New Zealand) than in the more developed ones (ie, all other regions plus Japan, Australia, and New Zealand). ${ }^{1}$ The proportion of older adults aged 60 years or older was $23 \%$ in 2013 and is expected to reach $32 \%$ in 2050 in the more developed countries. In the less developed regions, this proportion is expected to double between 2013 and 2050, increasing from $9 \%$ in 2013 to $19 \%$ in 2050 . Similarly, in the least developed countries (eg, Burundi), ${ }^{20}$ this proportion, which remained fairly stable at $\sim 5 \%$ for many decades, is also expected to double by $2050 .{ }^{1}$

This large increase in the proportion of elderly people in Sub-Saharan Africa emerges in a context where the main source of support for older people who are unable to care for themselves is the household and family. ${ }^{21,22}$ With few exceptions, formal pensions (whether contributory or not) or other social health care systems are virtually nonexistent, and when they do exist, they tend to pay minimal benefits and cover only a small fraction of the elderly population. ${ }^{23}$ Some available data show that, for example, in 2011, the percentage of older people beyond 60 years of age (the age of retirement) who benefited from a pension was $4 \%$ in Burundi. ${ }^{23}$ However, family solidarity norms may be weakened by the influence of Western values of individualism that result from modernization; ${ }^{21}$ emphasis on the nuclear family and the demise of extended family weaken older people's status and role. ${ }^{22}$ Rising economic hardships because of Burundi's stagnant economy may also contribute to weak support provided to older people, particularly in urban areas. ${ }^{21}$ Indeed, Aboderin ${ }^{21}$ suggests that the decline in support for older people reflects more an incapacity to take care of them (in terms of financial resources) than a rise of individualism. It also seems that respect and support in old age is increasingly viewed as something that must be earned, and the care that is given to elderly people is more and more a reciprocal measure of the care they gave to their children when they were young. ${ }^{19,21}$ In other words, family solidarity currently seems to be more a question of choice than duty in Sub-Saharan countries. ${ }^{24}$ For example, retired or inactive (do not work anymore) older people are more welcome in the household if they can contribute to the solidarity by, for example, babysitting children. ${ }^{24}$

In addition, it seems important to take employment of children into account when discussing intergenerational solidarity. A survey of 4,995 older people (55 years and older) in seven capitals in Africa (Mali, Togo, Senegal, Burkina Faso, Niger, Ivory Coast, and Benin), which comprise the least developed countries in the world (except Ivory Coast), ${ }^{20}$ showed that approximately one person in four lives in a household headed by a person aged 55 years or older. ${ }^{25}$ These households can comprise six to ten people. This size results from difficulties the younger generation face to find a job and, therefore, live independently. In this context, parents help their children as much as they can (considering their limited economic resources). Therefore, it is not unusual that older people are responsible for their older children. In addition, because deaths caused by the human immunodeficiency virus and the acquired immunodeficiency syndrome are most common in those aged 15-50 years, it is likely that older people will face the loss of a child or children, which leaves them with obligations and responsibilities for grandchildren and other members of their extended families. ${ }^{19}$ Family solidarity is therefore a bidirectional phenomenon. 


\section{Aims and approach of the study}

To our knowledge, comparisons between Western and Sub-Saharan cultures have never been made, which may be because Africa is the youngest continent in the world. ${ }^{1}$ In this perspective, our objective was to assess attitudes toward the elderly among Burundian adults living in the capital city of Bujumbura and Belgian adults living in Belgium. To determine how immigration and the acculturation process may affect attitudes toward the aged, the attitudes of Burundians living in Belgium were also examined.

Sub-Saharan traditions of intergenerational solidarity could lead us to assume that positive attitudes are more prevalent in African than in Western societies, as it was hypothesized for comparisons between Eastern and Western countries. This may be the case when older adults keep working and take care of their unemployed children. This is however without taking into consideration the demographic and socioeconomic changes that Burundians underwent, changes that are likely to influence the status of, and therefore the attitudes toward, older people. Even if the old-age dependency ratio is currently quite stable in Burundi (dependency ratio: 5.8 in 1950, 6.0 in 2000, and projected to be 4.9 in 2020 and 7.2 in 2050) but not in Belgium (dependency ratio: 16.2 in 1950, 25.8 in 2000, and projected to be 31.6 and 45.7 in 2020 and 2050), ${ }^{17}$ Burundi is considered to be one of the least developed countries in the world, ${ }^{20}$ whereas Belgium is one of the most modern countries in Europe. ${ }^{16}$ Therefore, less social and economic resources available for older Burundians' health care may predict more negative attitudes toward them among the population compared to Belgians. We might also hypothesize that Burundians living in Belgium will have similar attitudes toward older people compared with Belgians because attitudes are more a question of socioeconomic resources than culture.

\section{Participants and methods Participants}

This study was conducted in accordance with the principles outlined in the Declaration of Helsinki. Three groups of respondents were targeted for recruitment into this study. The Belgian group participants $(\mathrm{n}=27)$ were born and are living in Belgium (BE/BE), the Burundian group participants $(n=32)$ were residents of the capital Bujumbura and born in Burundi (BU/BU), and the Belgian Burundian participants $(n=29)$ were residents of Belgium for a minimum of 1 year and born in Burundi (BE/BU). All participants were adults or middle aged.

The $\mathrm{BE} / \mathrm{BE}$ and $\mathrm{BU} / \mathrm{BU}$ participants were recruited by word of mouth. Recruitment in Burundi was enabled by the presence of two contact persons who collected the data in
Bujumbura. BE/BU participants were recruited in a general meeting of Burundians living in Belgium. All participants had sufficient knowledge of French to understand and answer the questionnaires.

\section{Data collection}

Data were collected between November 2013 and February 2014. A consent form and a brief introductory paragraph describing the general purpose of the study were included with the questionnaires. A written consent form was obtained by each participant before participating in the study. The participants were then asked to complete demographic data and respond to questions assessing their attitudes toward older adults. More specifically, the questionnaires were presented in this order: 1) the open-ended Image-of-Aging question; ${ }^{8}$ 2) questions about the age at which someone stops being considered young and is considered old ${ }^{26} 3$ ) demographic data; and finally, 4) the Fraboni Scale of Ageism - Revised (FSA-R). ${ }^{27}$ The questionnaires were all self-reported. However, BU/BU participants explained that they were not used to filling out such surveys. Therefore, they preferred to respond verbally to the questions asked by the contact person, who then noted their answers.

\section{Measures}

\section{Demographic characteristics}

Demographic data were collected, including chronological age, sex, nationality, marital status, educational level, and employment status.

\section{Attitudes toward older people}

To assess participants' view of which periods of life correspond to youth and old age, ${ }^{26}$ they were asked to be specific in answering (in years), "At what age does someone stop being young?" (end of youth) and "At what age does a person become old?" (beginning of old age).

Ageist attitudes were assessed using two different self-reported measures, the open-ended Image-of-Aging question $^{8,28}$ and the French version of the FSA-R..$^{27}$

The open-ended Image-of-Aging question ${ }^{8,28}$ asked participants "When you think of old persons, what are the first 5 words or phrases that come to mind?". We believe that this measure is interesting because it allows respondents to produce their own representations of aging without preestablished statements. Responses were coded by external evaluators (mean age: $32.21 \pm 9.92$ years) on an 11-item scale ranging from -5 (extremely negative, eg, mistreatment) to +5 (extremely positive, eg, wisdom) with reference to old people. All words were assessed by the same people. Two random orders were created, and each list was assessed by 12 people, 
which made a total of 24 assessments for each word. The external evaluators were 23 Belgians living in Belgium and one French evaluator living in Belgium. Interrater reliability was high (intraclass correlation coefficient $=0.96$ ). The value of the intraclass correlation coefficient did not differ if the French evaluator was excluded, which led us to include his results. To limit the number of responses to evaluate, produced words such as synonyms were grouped together as nouns and adjectives (eg, "Frail" and "frailty" were regrouped as "frailty" and "lack of physical force" and "physically weak" were grouped as "weakness"). This enabled us to calculate a total score using the valence of each word (a higher score meant a more positive representation of aging).

The FSA-R, ${ }^{27}$ which is an explicit measure of ageism, contains 14 items about ageism that are measured using a Likert-type scale ranging from 1 (strongly disagree) to 5 (strongly agree). Besides the total score, three factors can be derived from the scale: stereotypes, which indicate negative stereotypes about the elderly (eg, "Many older people just live in the past."); affective attitudes or the negative emotional attitudes toward older adults (eg, "I personally would not want to spend much time with an old person."); and separation, which examines the tendency to avoid contact with older adults either directly or indirectly (eg, "It is best that old people live where they won't bother anyone."). A higher total score means a higher level of ageism, and higher scores on the subscales reflect negative stereotypes and affective attitudes toward older adults and a willingness to avoid them.

\section{Statistical analyses}

All statistical data analyses were performed using Statistica 12 (Statsoft, Tulsa, OK, USA), and $P<0.05$ was used as a criterion for statistical significance.

Parametric analyses were performed. Equivalent nonparametric tests were also used when the data were not normally distributed or when the variance was not homogeneous. For more consistency and when results of parametric and nonparametric tests led to the same conclusions, results of parametric tests were presented. If necessary, results of nonparametric tests were also presented.

Preliminary analysis of variance (ANOVA) and chisquared analyses were conducted to establish whether demographic characteristics (including age, sex, marital status, and educational level) were similar across groups.

ANOVA and Kruskal-Wallis tests, as well as related post hoc pairwise comparisons, were used to assess group effects on attitudes toward older adults. We also reported observed partial eta-squared $\left(\eta_{\mathrm{p}}^{2}\right)$ value, a measure of effect size, where 0.01 is a small effect size, 0.06 is medium effect size, and
0.14 is large effect size..$^{29}$ In addition, frequency analyses were used for the open-ended Image-of-Aging question to establish the words most frequently cited in each group. To illustrate the participants' representation of aging, we created a word cloud for each group using the website http://www.wordle. net/create.${ }^{30}$ The size of each word was correlated with its frequency (ie, the more often a word was cited, the larger the cloud), and the color of each word represented its valence.

Pearson's $(r)$ and Spearman $\left(r_{\mathrm{s}}\right)$ correlations were also computed between attitudes toward older adults and the time spent in Belgium among the BE/BU participants.

\section{Results}

\section{Background characteristics}

The $\mathrm{BE} / \mathrm{BE}$ group ranged in age from 21 years to 50 years (mean $=36.04, \mathrm{SD}=7.69$ ), and the $\mathrm{BE} / \mathrm{BU}$ and $\mathrm{BU} / \mathrm{BU}$ ages, respectively, ranged from 20 years to 54 years (mean $=37.07, \mathrm{SD}=9.77)$ and 20 years to 48 years (mean $=33.22, \mathrm{SD}=7.59$ ). The groups were comparable in terms of age, $F(2,85)=1.73, P=0.18$. Other participant demographics did not vary significantly by group, except for employment status (Table 1). The BE/BU participants had lived in Belgium for a minimum of 1 year and a maximum of 21 years (mean $=8.14, \mathrm{SD}=4.06$ ).

\section{Attitudes toward older adults}

The three groups did not differ in the age that would mark, in their opinion, the end of youth $\left(P=0.29, \eta_{\mathrm{P}}^{2}=0.03\right.$; Table 2$)$. However, we observed a significant effect of group for the age given for the beginning of old age $\left(P=0.002, \eta_{\mathrm{P}}^{2}=0.14\right)$. Post hoc analyses revealed that the BU/BU participants considered old age to begin at a younger age than the age given by the $\mathrm{BE} / \mathrm{BE}$ participants $(P=0.001)$, but the age reported by the $\mathrm{BE} / \mathrm{BU}$ participants did not differ from that of the $\mathrm{BU} / \mathrm{BU}$ $(P=0.08)$ and $\mathrm{BE} / \mathrm{BE}$ participants $(P=0.26)$.

ANOVA indicated a significant effect of group on ageism (Table 2), measured with the Image-of-Aging question $\left(P<0.001, \eta_{\mathrm{P}}^{2}=0.22\right)$ and the total score of the FSA-R $\left(P<0.001, \eta_{\mathrm{P}}^{2}=0.23\right)$. Tukey's honest significant difference tests showed that the $\mathrm{BU} / \mathrm{BU}$ participants had more negative attitudes toward older people than the $\mathrm{BE} / \mathrm{BE}(P<0.001)$ and $\mathrm{BE} / \mathrm{BU}(P=0.001)$ participants for both measures. In contrast, no differences were observed between the $\mathrm{BE} / \mathrm{BU}$ and $\mathrm{BE} / \mathrm{BE}$ participants for the Image-of-Aging question and the total score of the FSA-R ( $P=0.70$ and $P=0.50$, respectively). When examining the subscales of the FSA-R, similar results were obtained for post hoc analyses: the BU/BU participants expressed more negative stereotypes and separation behaviors toward the elderly, compared to the $\mathrm{BE} / \mathrm{BE}$ ( $P=0.001$ and 
Table I Demographic characteristics

\begin{tabular}{|c|c|c|c|c|c|}
\hline & BE/BE (n) & BE/BU (n) & BU/BU (n) & $\chi^{2}(d f)$ & $P$-value \\
\hline Sex & & & & $2.76(2)$ & 0.25 \\
\hline Female & $9(33.33)$ & $15(5 \mid .72)$ & $17(53.12)$ & & \\
\hline Male & $18(66.67)$ & $14(48.28)$ & $15(46.88)$ & & \\
\hline Marital status & & & & $5.64(6)$ & 0.46 \\
\hline Single & $13(48.15)$ & $8(27.59)$ & $15(48.39)^{\mathrm{a}}$ & & \\
\hline Married & $13(48.15)$ & $20(68.96)$ & $14(45.16)$ & & \\
\hline Separated & $0(0.00)$ & $0(0.00)$ & I (3.225) & & \\
\hline Widowed & I (3.70) & I (3.45) & I (3.225) & & \\
\hline Educational level & & & & $6.87(4)$ & 0.14 \\
\hline Primary and lower & $2(7.69)^{\mathrm{a}}$ & I (3.45) & $0(0.00)$ & & \\
\hline Secondary & $9(34.62)$ & $10(34.48)$ & $5(15.62)$ & & \\
\hline Higher & I5 (57.69) & $18(62.07)$ & $27(84.38)$ & & \\
\hline Employment status & & & & $26.18(8)$ & $<0.001$ \\
\hline Laborer & $8(33.33)^{b}$ & $4(16.67)^{c}$ & $0(0.00)^{d}$ & & \\
\hline Employee & $12(50.00)$ & $16(66.67)$ & $20(7 I .43)$ & & \\
\hline Self-employed worker & $4(16.67)$ & $0(0.00)$ & $3(I .7 I)$ & & \\
\hline Student & $0(0.00)$ & I (I2.50) & $5(17.86)$ & & \\
\hline Unemployed & $0(0.00)$ & $3(4.17)$ & $0(0.00)$ & & \\
\hline
\end{tabular}

Notes: Data presented as $\mathrm{n}(\%)$. ${ }^{\mathrm{a} D a t a}$ missing for one participant. ${ }^{\mathrm{b}} \mathrm{Data}$ missing for three participants. ${ }^{\mathrm{c}}$ Data missing for five participants. ${ }^{\mathrm{d} D a t a}$ missing for four participants.

Abbreviations: BE/BE, Begians living in Belgium; BE/BU, Burundians living in Belgium; BU/BU, Burundians living in Burundi.

$P<0.001$, respectively) and $\mathrm{BE} / \mathrm{BU}(P=0.02$ and $P=0.003$, respectively) participants. The BU/BU participants also had more negative emotional attitudes toward older people than the $\mathrm{BE} / \mathrm{BE}$ participants $(P=0.02$, but $P=0.15$ compared with the BE/BE participants).

On the Image-of-Aging question, a total of 69,74 , and 73 different words were produced by the $\mathrm{BE} / \mathrm{BE}, \mathrm{BE} / \mathrm{BU}$, and BU/BU participants, respectively, after grouping similar words together. The BU/BU group produced the lowest percentage of positive words (18\%) compared to the BE/BE and $\mathrm{BE} / \mathrm{BU}$ groups ( $41 \%$ and $38 \%$, respectively). In addition, the $\mathrm{BE} / \mathrm{BE}$ and $\mathrm{BE} / \mathrm{BU}$ groups produced $36 \%$ and $52 \%$ of negative words, respectively, and this percentage increased to $72 \%$ in the BU/BU group.

Overall (including positive and negative words), frequency analyses showed that the three most cited words by the BE/BE participants were "experience" (6.15\%), "dependence", and "grandparents" (each 4.62\%; Figure 1).

Among the BE/BU participants, "wisdom" (9.09\%) and "disease" (6.99\%) were the most frequently cited, followed by "experience", "frailty", and "respect", all cited by $5.59 \%$ of the participants (Figure 1).

Table 2 Comparisons of attitudes toward older adults

\begin{tabular}{|c|c|c|c|c|c|c|c|c|c|}
\hline & \multirow{2}{*}{$\begin{array}{l}\text { BE/BE, } \\
\text { mean } \pm \text { SD } \\
\text { (range) }\end{array}$} & \multirow{2}{*}{$\begin{array}{l}\text { BE/BU, } \\
\text { mean } \pm \text { SD } \\
\text { (range) }\end{array}$} & \multirow{2}{*}{$\begin{array}{l}\text { BU/BU, } \\
\text { mean } \pm \text { SD } \\
\text { (range) }\end{array}$} & \multirow[t]{2}{*}{$F(d f)^{a}$} & \multirow[t]{2}{*}{$P$-value } & \multirow[t]{2}{*}{$\eta_{\mathrm{P}}^{2}$} & \multicolumn{3}{|c|}{ Post hoc tests } \\
\hline & & & & & & & $\begin{array}{l}\text { BE/BE and } \\
\text { BE/BU, } \\
P \text {-value }\end{array}$ & $\begin{array}{l}\text { BE/BE and } \\
\text { BU/BU, } \\
P \text {-value }\end{array}$ & $\begin{array}{l}\text { BE/BU and } \\
\text { BU/BU, } \\
P \text {-value }\end{array}$ \\
\hline End of youth & $\begin{array}{l}41.73 \pm 15.02 \\
(20-80)^{b}\end{array}$ & $\begin{array}{l}43.32 \pm 12.35 \\
(18-65)^{b}\end{array}$ & $\begin{array}{l}39.87 \pm 8.62 \\
(30-60)^{b}\end{array}$ & $1.24(2,83)$ & 0.29 & 0.03 & 0.59 & 0.27 & 0.86 \\
\hline $\begin{array}{l}\text { Beginning of old } \\
\text { age }\end{array}$ & $\begin{array}{l}66.74 \pm 10.74 \\
(40-90)\end{array}$ & $\begin{array}{l}62.72 \pm 9.69 \\
(40-80)\end{array}$ & $\begin{array}{l}57.39 \pm 8.25 \\
(45-75)^{\mathrm{b}}\end{array}$ & $7.016(2,84)$ & 0.002 & 0.14 & 0.26 & 0.001 & 0.08 \\
\hline $\begin{array}{l}\text { Image-of-Aging } \\
\text { question }\end{array}$ & $\begin{array}{l}0.04 \pm 1.03 \\
(-1.90-2.03)\end{array}$ & $\begin{array}{l}-0.22 \pm 1.60 \\
(-3.1-2.46)\end{array}$ & $\begin{array}{l}-1.42 \pm 1.05 \\
(-2.88-2.64)\end{array}$ & II.73 $(2,85)$ & $<0.00 \mathrm{I}$ & 0.22 & 0.70 & $<0.001$ & 0.001 \\
\hline FSA-R total & $\begin{array}{l}28.22 \pm 5.03 \\
(20-4 I)\end{array}$ & $\begin{array}{l}30.17 \pm 6.63 \\
(15-40)\end{array}$ & $\begin{array}{l}36.30 \pm 7.23 \\
(19-55)\end{array}$ & $12.98(2,85)$ & $<0.001$ & 0.23 & 0.50 & $<0.001$ & 0.001 \\
\hline FSA-R stereotypes & $\begin{array}{l}14.96 \pm 3.49 \\
(9-23)\end{array}$ & $\begin{array}{l}16.03 \pm 4.20 \\
(6-22)\end{array}$ & $\begin{array}{l}19.04 \pm 4.92 \\
(7-29)\end{array}$ & $7.33(2,85)$ & 0.001 & 0.15 & 0.62 & 0.001 & 0.02 \\
\hline $\begin{array}{l}\text { FSA-R affective } \\
\text { attitudes }\end{array}$ & $\begin{array}{l}5.48 \pm 1.74 \\
(3-10)\end{array}$ & $\begin{array}{l}5.93 \pm 1.90 \\
(2-9)\end{array}$ & $\begin{array}{l}6.84 \pm 1.90 \\
(3-11)\end{array}$ & $4.24(2,85)$ & 0.02 & 0.09 & 0.64 & 0.02 & 0.15 \\
\hline FSA-R separation & $\begin{array}{l}7.78 \pm 2.47 \\
(5-15)\end{array}$ & $\begin{array}{l}8.21 \pm 3.67 \\
(5-13)\end{array}$ & $\begin{array}{l}10.42 \pm 2.69 \\
(5-16)\end{array}$ & $9.56(2,85)$ & $<0.001$ & 0.18 & 0.80 & $<0.001$ & 0.003 \\
\hline
\end{tabular}

Notes: aResults for analyses of variance (post hoc pairwise comparisons with Tukey's HSD tests). ${ }^{\text {} D a t a}$ missing for one participant.

Abbreviations: BE/BE, Begians living in Belgium; BE/BU, Burundians living in Belgium; BU/BU, Burundians living in Burundi; SD, standard deviation; $d f$, degrees of freedom; $\eta_{p}^{2}$, partial eta squared; FSA-R, Fraboni Scale of Ageism - Revised; HSD, honest significant difference. 


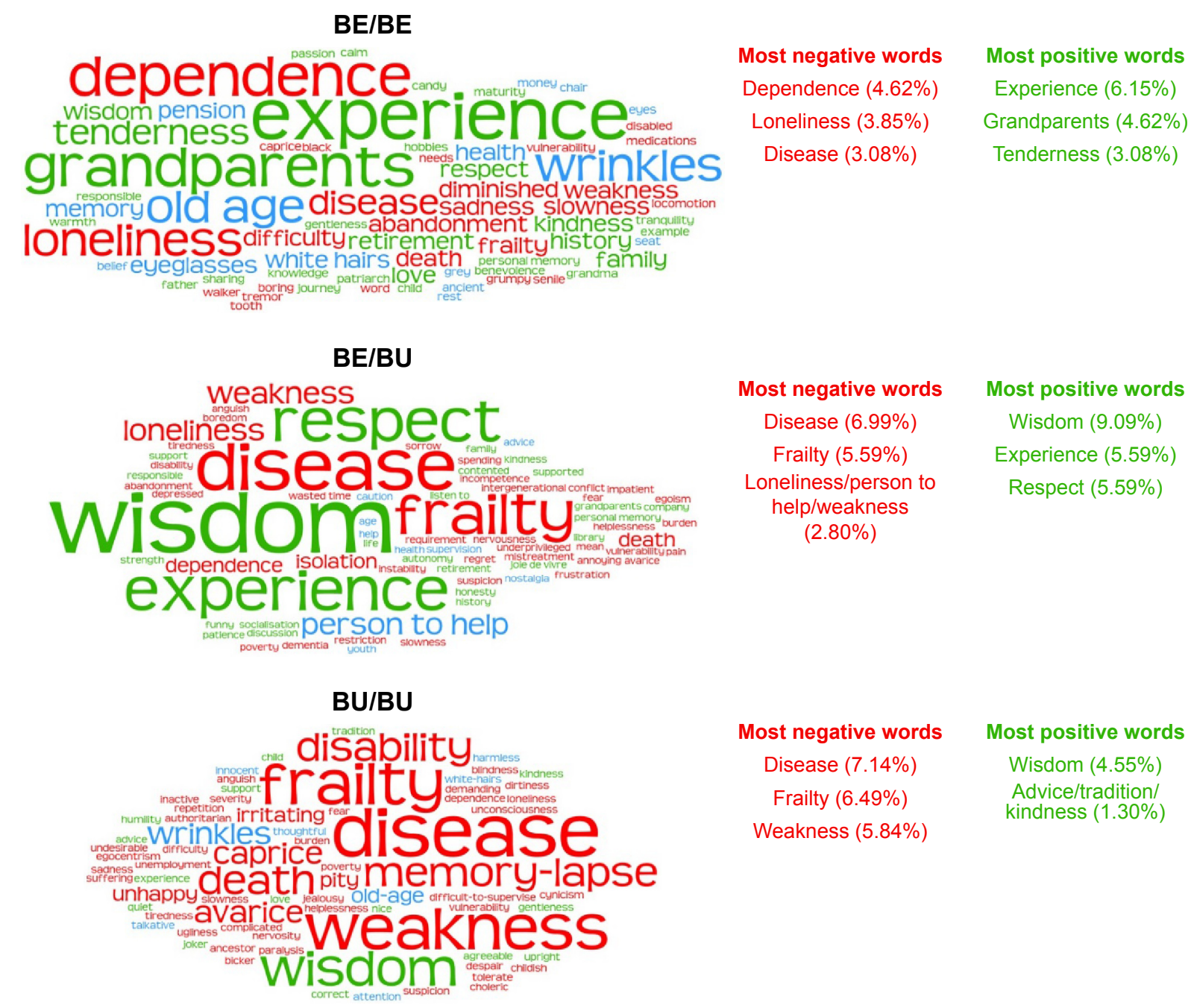

Figure I Words produced by BE/BE, BE/BU, and BU/BU and top three most cited negative and positive words (percentage of participants who cited this word). Notes: Red denotes negative words $(-5$ to $-I)$, green denotes positive words $(+I$ to +5$)$, and blue denotes neutral words $(-I$ to $+I)$. Abbreviations: $\mathrm{BE} / \mathrm{BE}$, Begians living in Belgium; $\mathrm{BE} / \mathrm{BU}$, Burundians living in Belgium; BU/BU, Burundians living in Burundi.

Additionally, among the BU/BU participants, the three most cited words were "disease", "frailty", and "weakness" (7.14\%, $6.49 \%$, and $5.84 \%$ of the participants, respectively), which were all judged to be negative (Figure 1).

Correlation analyses indicated no significant relationship in the BU/BU group between the number of years spent in Belgium and perception of end of youth $(r=0.01, P=0.94)$, beginning of old age ( $r=0.11, P=0.55)$, and ageism measured by the Image-of-Aging question $\left(r_{\mathrm{s}}=0.18, P=0.35\right)$ or the total score of the FSA-R $\left(r_{\mathrm{s}}=-0.14, P=0.47\right)$.

\section{Discussion}

The present study extends the literature by comparing attitudes toward older people between a European and a SubSaharan culture. According to the modernization theory and the role of socioeconomic resources, we hypothesized that Burundian and Belgian adults living in Belgium perceive older adults less negatively than Burundian adults living in Bujumbura. The lack of funds allocated to support older people (eg, pension and health care system) in this least developed country can be perceived as a threat that undermines their status. ${ }^{15,16}$ This observation is important because the position that a group occupies in society's hierarchy allows inferences concerning its competence, with high-status people perceived as being competent, while low-status people stereotyped as being incompetent. ${ }^{4}$ It is important to take into account all variables that can lead us to subtle variability in our hypothesis. A study conducted in European countries ${ }^{16}$ suggests that the perception of the status of older people may be raised when more of them are employed because this may assure older people a better standard of living and, therefore, compensate for the lack of material resources. Similarly, even if family solidarity values encourage younger adults to take care of their older 
parents in Sub-Saharan African cultures, older people living in capital cities in the least developed countries in the world sometimes have a duty to keep working to economically care for their unemployed children. ${ }^{25}$

First, when considering answers provided by groups to determine periods of youth and old age, we observed no difference between the groups in estimating the end of youth. Concerning the beginning of old age, while the BU/BU participants considered someone to be old at 57 years, the $\mathrm{BE} / \mathrm{BE}$ participants set this age at 67 years and the $\mathrm{BE} / \mathrm{BU}$ participants set it at 63 years. This is not surprising considering the more medically based representation of aging among the BU/BU participants and the difference in life expectancy between the two countries: 54 years in Burundi and 80 years in Belgium for the $2011-2015$ period. ${ }^{31}$ Note that while the beginning of old age among the BU/BU participants approximately corresponds to the life expectancy, it corresponds roughly to the retirement age in Belgium.

Second, answers to questionnaires assessing ageism revealed that the $\mathrm{BU} / \mathrm{BU}$ participants have more negative attitudes toward older people than the $\mathrm{BE} / \mathrm{BU}$ and $\mathrm{BE} / \mathrm{BE}$ participants. These effects were moderate to large. ${ }^{29}$ The valence of words given in answer to the Image-of-Aging question $^{8,28}$ revealed that the BU/BU participants had a more negative image of aging than the $\mathrm{BE} / \mathrm{BE}$ and $\mathrm{BE} / \mathrm{BU}$ participants, who did not differ from each other and who had a more nuanced representation of older people. Among the BU/BU participants, descriptive statistics showed that they provided the most negative words $(72 \%)$ and that the most frequent words suggested that older people are primarily considered to be ill, frail, and weak. However, even if negative words (eg, disease, dependence) were cited among the $\mathrm{BE} / \mathrm{BU}$ ( $38 \%$ of the words) and $\mathrm{BE} / \mathrm{BE}$ ( $41 \%$ of the words) participants, $52 \%$ of the words among the $\mathrm{BE} / \mathrm{BU}$ participants and $36 \%$ among the $\mathrm{BE} / \mathrm{BE}$ participants were positive words and showed that older people are also considered to be wise and experienced. Similar to this result, answers given on the FSA- ${ }^{27}$ showed that the $\mathrm{BU} / \mathrm{BU}$ participants have more ageist attitudes toward the elderly compared to the $\mathrm{BE} / \mathrm{BU}$ and $\mathrm{BE} / \mathrm{BE}$ participants. This means that they have not only more negative stereotypes but also more negative feelings toward older people and show a greater tendency to avoid them.

Analyses of representations of the elderly among the BU/ BU participants suggest that, in Burundi, older people comprise those who can no longer work and contribute to intergenerational family solidarity. Studies conducted in Europe showed that older people are perceived as less competent in countries where fewer older people participated in paid ${ }^{16,32}$ as well as in volunteer work. ${ }^{32}$ Therefore, ability to work and to contribute to intergenerational solidarity - that may be determined by voluntary activities such as babysitting - allow older people to still be perceived as competent, which was not the case among the BU/BU participants. On the contrary, their answers (ie, older adults are perceived as ill and frail) suggest that they consider older people to be inactive and even possibly a burden for their relatives.

Moreover, since participants from Burundi were all employed adults living in Bujumbura, it is possible that they did not need financial resources from their older relatives. In this case, older adults might not have considered the possibility to contribute to intergenerational solidarity by helping financially their younger relatives. To sum up, older adults' inability to work and to contribute to intergenerational solidarity might explain why the $\mathrm{BU} / \mathrm{BU}$ participants perceive them more negatively. This might be particularly true considering the precarity of the health care system in Burundi and the fact that family solidarity is increasingly perceived as something that must be reciprocal. ${ }^{19,21}$ It is important to highlight that negative attitudes toward the elderly among the BU/BU participants do not necessarily mean that they do not value intergenerational family solidarity. They might continue to meet the needs of their older relatives in a country where the health system is underdeveloped. Nevertheless, since they might perceive older adults as having been or being unable to reciprocate benefits they receive, they might have negative attitudes toward them. In addition, the association between aging and disease was expressed more strongly by the BU/BU participants compared with the BE/BE and $\mathrm{BE} / \mathrm{BU}$ participants, which may be explained by the fact that the health situation remains precarious in Burundi, with a life expectancy that is much lower than that of Belgium. ${ }^{31}$

Taken together, these results support the idea that ageism is more a question of available resources than culture, as predicted. Our hypothesis is also supported by the lack of difference in ageism scores between the $\mathrm{BE} / \mathrm{BE}$ and $\mathrm{BE} / \mathrm{BU}$ participants and also because the time spent in Belgium which may reflect the degree of acculturation - is not linked to the level of ageism among the BE/BU participants. Nevertheless, even if the time spent in Belgium may reflect the degree of acculturation, these results need to be replicated with larger and more representative samples. Therefore, we cannot preclude that the similarity between the $\mathrm{BE} / \mathrm{BE}$ and $\mathrm{BE} / \mathrm{BU}$ participants could also be partially explained by a process of acculturation and, more particularly, by the assimilation of individualistic values. Indeed, North and Fiske ${ }^{15}$ found in their meta-analysis that cultural individualism predicted more 
positive evaluations toward older adults in industrialized societies. They suggested that in modernized countries, individualism may lead people to place an increased emphasis on individual welfare and respect, which might heighten appreciation for older adults' experience and insight. On the contrary, collectivist values in modernized countries might predict more negative attitudes: younger adults may feel resentment toward older adults who demand support without being able to contribute to society's newfound emphasis on manual labor and new technologies.

Finally, besides the possible influence of the Belgian socio-economic context and culture on the BE/BU participants' attitudes toward older adults, the personal factors that led them to immigrate may also contribute in explaining why they have more positive attitudes toward older adults than the BU/BU participants. Indeed, it has been shown that Sub-Saharan immigrants in Belgium have high educational levels, ${ }^{33}$ which has been associated with less negative attitudes toward older adults in the literature. ${ }^{34}$ However, in our study, the educational level of the $\mathrm{BE} / \mathrm{BU}$ and $\mathrm{BU} / \mathrm{BU}$ participants did not differ. Moreover, it is possible that the $\mathrm{BE} / \mathrm{BU}$ participants who emigrated had the possibility to leave their country because they did not have to take care of dependent older relatives in Burundi. Further studies are therefore necessary to investigate these factors.

\section{Limits and future directions}

Our study provides interesting results that allow us to understand cross-cultural differences in ageism between a European and a Sub-Saharan country, but our findings need to be interpreted with caution because of several limitations.

It would have been interesting if words that were produced during the Image-of-Aging question were assessed by evaluators in the same groups as the participants to compare subtleties in the valence between groups evaluating the same word. It is possible that the same word (eg, disease) would have been assessed more negatively among the $\mathrm{BU} / \mathrm{BU}$ participants than among the $\mathrm{BE} / \mathrm{BE}$ or $\mathrm{BE} / \mathrm{BU}$ participants.

Moreover, the study should be replicated on larger and more representative samples. Indeed, methods of recruitment for this study were limited: the BU/BU participants were recruited by word of mouth realized by contact persons in Bujumbura, and the BE/BU participants were added into the study during a general meeting of Burundians living in Belgium. The BE/BE participants with sociodemographic characteristics that were similar to those of the $\mathrm{BU} / \mathrm{BU}$ and $\mathrm{BE} / \mathrm{BU}$ participants were then recruited in order to match the three groups as far as possible. Therefore, even if the effect sizes were moderate to large, the samples were not representative of the general population in Burundi and Belgium because of their small size. This lack of representativeness might influence the results we obtained. In fact, at least $50 \%$ of the participants in each group had a high educational level (ie, higher than secondary), and a study suggested that higher education might be associated with fewer negative attitudes toward older adults. ${ }^{34}$ Similarly, the BU/BU sample included only people living in Bujumbura, an urban area. Therefore, laborers with a lower educational level were underrepresented. Indeed, $88 \%$ of the population in Burundi currently lives in rural areas, ${ }^{35}$ and a large part of this population is engaged in farming, which means that their average educational level is probably lower than that of our sample. ${ }^{36}$ However, in rural areas, lower levels of technology and domestic resources (eg, energy) might necessitate closer cooperation between the generations for domestic and subsistence tasks. In this context, older people might have a more important role (eg, passing down to younger relatives techniques of farming, taking care of grandchildren when parents are working), which might positively influence attitudes toward them. It is also essential to highlight that our study was conducted among Burundian adults living in Bujumbura who had a job. According to previous research on intergenerational family solidarity, ${ }^{25}$ attitudes toward older adults among the BU/BU participants might have been more positive if the survey was conducted among the unemployed BU/BU people who received financial help from their older relatives. Unemployment in Burundi is mainly an urban phenomenon and particularly affects the young. In 2008, youth unemployment was three times higher than that in the 25- to 64-year-old age group and was estimated as $14.4 \%$ in Bujumbura, $9 \%$ in Gitega, and $6.5 \%$ in Karusi. ${ }^{36}$ Therefore, we suggest that it is not currently so much the level of education or the area in which participants live (rural versus urban) that influences the attitudes of adults toward elders, but rather the contribution of older adults to the family solidarity, irrespective of whether this contribution is financial. However, the progressive modernization and therefore the migration of the adult labor force in rural areas could affect the elderly profoundly in the future: ${ }^{19}$ intergenerational cooperation in homes and farms would disappear and older people living alone in rural areas would be more numerous. As suggested by a study conducted among older Chinese adults, ${ }^{37}$ it is possible that urban elders could reap more from the process of modernization, such as a higher living standard, more access to digital products, and better social security protection. These modifications could raise 
the status of older adults living in urban areas and lead their younger counterparts to perceive older adults living in urban areas more positively than older adults living in rural areas, who will be increasingly isolated and dependent on financial resources of their relatives working in town.

In future research, it would also be interesting to include measures related to cultural variables (eg, measure of individualism) in order to investigate if acculturation influences attitudes toward older people among immigrants. Moreover, it would be necessary to investigate in detail possible confounding factors, such as those that lead the BE/BU participants to immigrate into Belgium, in order to establish how these emigration/immigration factors can influence attitudes toward older adults.

Finally, our findings are limited to two countries, and we cannot make any generalizations to other societies or speak to broad differences between industrialized and least developed countries. These results need to be replicated by comparing other European and sub-Saharan countries.

\section{Conclusion}

Our study found that Burundian adults living in Burundi generally perceive older adults more negatively than Burundian and Belgian adults living in Belgium. We believe that these findings suggest the necessity of the availability of more social and economic resources for older people's health care in the least developed countries to improve attitudes toward them among their younger counterparts.

\section{Acknowledgment}

This work was supported by the Fund for Scientific Research (FRS - FNRS), Belgium, to Manon Marquet (research fellow) and Sarah Schroyen (fresh grant).

\section{Disclosure}

The authors report no conflicts of interest in this work.

\section{References}

1. Population Division, Department of Economic and Social Affairs [webpage on the Internet]. World Population Ageing 2013. New York: United Nations Publications; 2013. Available from: http://www. un.org/en/development/desa/population/publications/pdf/ageing/ WorldPopulationAgeing2013.pdf. Accessed January 28, 2016.

2. Butler RN. Age-ism: another form of bigotry. Gerontologist. 1969;9(4): 243-246.

3. Fiske ST, Cuddy AJ, Glick P, Xu J. A model of (often mixed) stereotype content: competence and warmth respectively follow from perceived status and competition. J Pers Soc Psychol. 2002;82(6):878-902.

4. Cuddy AJ, Fiske ST. Doddering but dear: process, content, and function in stereotyping of older persons. In: Nelson TD, editor. Ageism. Cambridge: MIT Press; 2002:3-26.

5. Cuddy AJ, Fiske ST, Kwan VS, et al. Stereotype content model across cultures: towards universal similarities and some differences. Br J Soc Psychol. 2009;48(pt 1):1-33.
6. Sung K. Elder respect: exploration of ideals and forms in east Asia. J Aging Stud. 2001;15(1):13-26.

7. Cuddy AJ, Norton MI, Fiske ST. This old stereotype: the pervasiveness and persistence of the elderly stereotype. $J$ Soc Issues. 2005;61(2): 267-285.

8. Levy B, Langer E. Aging free from negative stereotypes: successful memory in China among the American deaf. J Pers Soc Psychol. 1994;66(6):989-997.

9. Huang CS. Undergraduate students' knowledge about aging and attitudes toward older adults in east and west: a socio-economic and cultural exploration. Int J Aging Hum Dev. 2013;77(1):59-76.

10. Luo B, Zhou K, Jin EJ, Newman A, Liang J. Ageism among college students: a comparative study between U.S. and China. J Cross Cult Gerontol. 2013;28(1):49-63.

11. Löckenhoff CE, De Fruyt F, Terracciano A, et al. Perceptions of aging across 26 cultures and their culture-level associates. Psychol Aging. 2009;24(4):941-954.

12. Branco KJ, Williamson JB. Stereotyping and the life cycle: views of aging and the aged. In: Miller AG, editor. In the Eye of the Beholder: Contemporary Issues in Stereotyping. New York: Praeger; 1982:364-410.

13. Cowgill DO. Aging and modernization: a revision of the theory. In: Gubrium JF, editor. Late Life. Springfield, IL: Thomas; 1974:123-145.

14. Hamamura T. Are cultures becoming individualistic? A cross-temporal comparison of individualism-collectivism in the United States and Japan. Pers Soc Psychol Rev. 2012;16(1):3-24.

15. North MS, Fiske ST. Modern attitudes toward older adults in the aging world: a cross-cultural meta-analysis. Psychol Bull. 2015;141(5): 993-1021.

16. Vauclair CM, Marques S, Lima ML, Bratt C, Swift HJ, Abrams D. Subjective social status of older people across countries: the role of modernization and employment. J Gerontol B Psychol Sci Soc Sci. 2015;70(4): 650-660.

17. Population Division, Department of Economic and Social Affairs [webpage on the Internet]. World Population Prospects: The 2012 Revision. New York: United Nations Publications; 2013. Available from: http://esa.un.org/unpd/wpp/publications/Files/WPP2012_Volume-IIDemographic-Profiles.pdf. Accessed January 28, 2016.

18. United Nations [webpage on the Internet]. LDC Criteria. 2014. Available from: http://www.un.org/en/development/desa/policy/cdp/ldc/ 1dc_criteria.shtml. Accessed January 28, 2016.

19. Oppong C. Familial roles and social transformations older men and women in Sub-Saharan Africa. Res Aging. 2006;28(6):654-668.

20. World Bank World Development Indicators [webpage on the Internet]. Least Developed Countries: UN Classification. 2016. Available from: http://data.worldbank.org/region/LDC. Accessed January 28, 2016.

21. Aboderin I. Decline in material family support for older people in urban Ghana, Africa: understanding processes and causes of change. J Gerontol B Psychol Sci Soc Sci. 2004;59(3):S128-S137.

22. Cohen B, Menken J. Aging in Sub-Saharan Africa: Recommendations for Furthering Research. Washington, DC: National Academies Press; 2006.

23. International Labour Office [webpage on the Internet]. World Social Protection Report 2014/15. Building Economic Recovery, Inclusive Development and Social Justice. 2014. Available from: http://www. ilo.org/wcmsp5/groups/public/---dgreports/---dcomm/documents/ publication/wcms_245201.pdf. Accessed January 28, 2016.

24. Vignikin K. Famille et relations intergénérationnelles. Réflexions sur les évolutions en cours en Afrique. [Family and intergenerational relationships. Toughts about current evolutions in Africa]. In: Antoine P, editor. Les Relations Intergénérationnelles en Afrique. Approche Plurielle. [Intergenerational Relationships in Africa. A Pluralist Approach]. Paris: CEPED; 2007:19-30. French.

25. Antoine P. La place et les activités des personnes âgées dans sept capitales ouest africaines. [Place and activities of the elderly in seven capitals in West Africa]. In: Antoine P, editor. Les Relations Intergénérationnelles en Afrique. Approche plurielle. [Intergenerational Relationships in Africa. A Pluralist Approach]. Paris: CEPED; 2007:31-62. French. 
26. Levy BR, Zonderman AB, Slade MD, Ferrucci L. Memory shaped by age stereotypes over time. J Gerontol B Psychol Sci Soc Sci. 2012; 67(4):432-436.

27. Boudjemadi V, Gana K. L'âgisme: adaptation française d'une mesure et test d'un modèle structural des effets de l'empathie, l'orientation à la dominance sociale et le dogmatisme sur l'âgisme. [Ageism: French adaptation of a measure and structural model testing the effects of empathy, dogmatism and social dominance orientation on ageism]. Can J Aging. 2009;12(4):371-389. French.

28. Levy B. Stereotype embodiment: a psychosocial approach to aging. Curr Dir Psychol Sci. 2009;18(6):332-336.

29. Cohen J. Statistical Power Analysis for the Behavioral Sciences. 2nd ed. Hillsdale, NJ: Lawrence Erlbaum Associates; 1988.

30. Wordle. [webpage on the Internet]. Feinberg J. 2014. Available from: http://www.wordle.net/create. Accessed July 19, 2016.

31. World Bank World Development Indicators [webpage on the Internet]. Life Expectancy at Birth, Total (Years). 2016. Available from: http:/ data.worldbank.org/indicator/SP.DYN.LE00.IN/countries. Accessed January 28, 2016.

32. Bowen CE, Skirbekk V. National stereotypes of older people's competence are related to older adults' participation in paid and volunteer work. J Gerontol B Psychol Sci Soc Sci. 2013;68(6):974-983.

33. Schoumaker B, Schoonvaere Q. L'immigration subsaharienne en Belgique. Etat des lieux et tendances récentes. [Sub-Saharan immigration in Belgium. Report and recent trends]. In: Mazzocchetti J, editor. Migrations Subsahariennes et Condition Noire en Belgique: à la Croisée des Regards. [Sub-Saharan Migrations and the Condition of Black People in Belgium: Different Persepctives]. Louvain-la-Neuve: Academia; 2014:65-94. French.
34. Gallagher S, Bennett KM, Halford JC. A comparison of acute and long-term health-care personnel's attitudes towards older adults. Int J Nurs Pract. 2006;12(5):273-279.

35. World Bank World Development Indicators [webpage on the Internet]. Urban Population (\% of Total). 2016. Available from: http://data.worldbank.org/indicator/SP.URB.TOTL.IN.ZS. Accessed January 28, 2016.

36. Système des Nations Unies au Burundi [United Nations in Burundi] [webpage on the Internet]. Agenda pour le développement post-2015. Rapport sur les consultations nationales au Burundi. [Agenda for the Post-2015 Development. Report on National Consultations in Burundi]. 2014. Available from: http://www.bi.undp.org/content/ $\mathrm{dam} /$ burundi/docs/publications/UNDP-bi-Agenda $\% 20$ pour\%20 le\%20developpement\%20Post-2015.pdf. Accessed January 28, 2016. French.

37. Chow N, Bai X. Modernization and its impact on Chinese older people's perception of their own image and status. Int Soc Work. 2011; 54(6):800-815.
Clinical Interventions in Aging

\section{Publish your work in this journal}

Clinical Interventions in Aging is an international, peer-reviewed journal focusing on evidence-based reports on the value or lack thereof of treatments intended to prevent or delay the onset of maladaptive correlates of aging in human beings. This journal is indexed on PubMed Central, MedLine,

\section{Dovepress}

CAS, Scopus and the Elsevier Bibliographic databases. The manuscript management system is completely online and includes a very quick and fair peer-review system, which is all easy to use. Visit http://www.dovepress. $\mathrm{com} /$ testimonials.php to read real quotes from published authors. 